\title{
A IMPRENSA SERTANEJA COMO FONTE DE PESQUISA: APONTAMENTOS ACERCA DO JORNAL O COMBATE
}

\author{
LA PRENSA SERTANEJA COMO FUENTE DE INVESTIGACIÓN: NOTAS \\ SOBRE EL PERIÓDICO O COMBATE
}

\author{
Maria Aparecida Silva de Sousa \\ Universidade Estadual do Sudoeste da Bahia - UESB \\ Lattes: http://lattes.cnpq.br/1717712438822665 \\ Endereço eletrônico: mariacida3@yahoo.com.br \\ José Rubens Mascarenhas de Almeida \\ Universidade Estadual do Sudoeste da Bahia - UESB \\ Lattes: http://lattes.cnpq.br/3920900756591288 \\ ORCID: https://orcid.org/0000-0002-0232-5461 \\ Endereço Eletrônico: rubens.mascarenhas@uesb.edu.br
}

\begin{abstract}
Resumo
Os estudos sobre a história da imprensa no Brasil têm tido consideráveis avanços nos últimos anos. De fato, pesquisadores dessa área têm dado grande contribuição ao analisarem o papel dos periódicos no processo de formação do Estado e da Nação brasileiros, seja no Oitocentos, quando as linhas de definição acerca da identidade nacional foram esboçadas e consolidadas, seja no século XX, a partir das novas demandas impostas pela implantação da República (1889) e a abolição da escravidão um ano antes (1888). Todavia, a despeito desses importantes estudos, a análise acerca da imprensa existente nas áreas interioranas e, mais especificamente, nos sertões da Bahia, ainda se constitui um campo em aberto para novas investigações. $O$ artigo discute a importância da imprensa periódica como fonte documental e apresenta algumas possibilidades de pesquisa a partir do Jornal $O$ Combate, um dos mais importantes e duradouros que circulou em Vitória da Conquista entre os anos de 1929, quando foi criado, e 1964.
\end{abstract}


Palavras-chave: Imprensa. Sertões. Jornal O Combate. Intelectuais. Fonte de pesquisa.

\begin{abstract}
Resumen
Los estudios sobre la historia de la prensa en Brasil han progresado considerablemente en los últimos años. De hecho, los investigadores en esta área han hecho una gran contribución al analizar el papel de los periodicos en el proceso de formación del Estado y la Nación brasileños, ya sea en el siglo XIX, cuando se definieron y consolidaron las líneas de definición sobre identidad nacional, ya sea en el siglo XX, de las nuevas demandas impuestas por la implantación de la República (1889) y la abolición de la esclavitud un año antes (1888). Sin embargo, a pesar de estos importantes estudios, el análisis de la prensa en las áreas interiores y, más específicamente, en el interior de Bahía, sigue siendo un campo abierto para futuras investigaciones. El artículo analiza la importancia de la prensa periódica como fuente documental y presenta algunas posibilidades de investigación basadas en el periódico $O$ Combate, uno de los más importantes y duraderos que circuló en Vitória da Conquista entre los años 1929, cuando se creó, y 1964.
\end{abstract}

Palabras clave: Prensa. Sertões. Periódico O Combate. Intelectuales. Fuente de investigación.

Entre os meses de agosto e dezembro de 2020, coordenamos um projeto de extensão nas dependências da Universidade Estadual do Sudoeste da Bahia, campus de Vitória da Conquista. Intitulado Intelectuais e Imprensa nos Sertões da Bahia, o mesmo foi motivado pela necessidade de recuperar a importância do papel exercido por intelectuais que atuaram na imprensa escrita em Vitória da Conquista e em Caetité, no sertão da Bahia, em fins do século XIX e no decorrer do XX. No processo de execução debateu-se questões políticas, econômicas e sociais que mobilizaram alguns desses intelectuais, a exemplo de João Gumes (1855-1930), Laudionor Brasil (1901-1950) e Camillo de Jesus Lima (1912-1975), como porta-vozes na denúncia e no posicionamento sobre temas de grande relevância em um período marcado por importantes transformações políticas e econômicas. Durante o evento, pesquisadores debateram questões teórico-metodológicas e apresentaram os resultados de suas pesquisas sobre a temática. ${ }^{\mathrm{i}}$ Com a parceria do Arquivo Municipal de Vitória da Conquista ${ }^{\mathrm{ii}}$, 


\section{A IMPRENSA SERTANEJA COMO FONTE DE PESQUISA: APONTAMENTOS ACERCA DO JORNAL O COMBATE}

foi possível também refletir sobre as fontes documentais que compõem o seu acervo, com foco nos antigos periódicos produzidos na cidade nas primeiras décadas do século $\mathrm{XX}$. $\mathrm{O}$ presente artigo, assim, intenta apresentar algumas possibilidades de pesquisa a partir, sobretudo, do conteúdo abordado pelo jornal "O Combate", um dos mais antigos e que também dispõe de uma numeração sequenciada mais completa. Antes, porém, falemos um pouco sobre os estudos históricos acerca da Imprensa no Brasil.

\section{As origens da Imprensa no Brasil}

Certamente um dos primeiros autores a tratar sobre a história da Imprensa no Brasil foi Nelson Werneck Sodré (1999), numa obra que se tornou referência para os estudiosos da temática, publicada, originalmente, em 1966. Em História da Imprensa no Brasil, o autor buscou traçar um amplo quadro do periodismo associando-o às mudanças políticas ocorridas na configuração do Estado desde a ruptura dos laços coloniais que atavam colônia e metrópole portuguesa até o regime republicano. Interessava, então, ao autor, inspirado na teoria marxista vigente em sua época, discutir as estreitas relações entre as mudanças econômicas no Brasil e o surgimento da imprensa (SODRÉ, 1999).

Sodré (1999) chama a atenção para a instalação tardia da imprensa no Brasil, ocorrida somente após a instalação da família real no Rio de Janeiro, em 1808, se comparada a algumas áreas da América espanhola, a exemplo do México (em 1539) e no Peru (em 1583). Todavia, é sabido que, mesmo com o impedimento de instalação de tipografias na colônia americana, assim como a de circulação de livros considerados proibidos, eram frequentes as denúncias de difusão desse tipo de material. Não à toa, as devassas instaladas por ocasião da Inconfidência Mineira (1789) e da Conjuração Baiana (1798) esbarraram com diversos livros de teor filosófico em casas de alguns dos denunciados. ${ }^{\text {iii }}$

Assim, a história da imprensa no Brasil relaciona-se diretamente a acontecimentos políticos e econômicos que marcaram a ruptura do domínio português sobre sua colônia americana em princípios do século XIX. Em 1808, foi criada a Gazeta do Rio de Janeiro, destinada a propalar os feitos do então príncipe regente, d. João. Poucos anos depois, a Bahia protagonizou a criação do segundo jornal em terras americanas. Em 1811, começou a circular a Idade d'ouro do Brazil, com perfil semelhante ao periódico fluminense. Na esteira das transformações provocadas pelas ondas revolucionárias de fins do século XVIII e a ampla 

ACERCA DO JORNAL O COMBATE

difusão das ideias liberais no mundo Ocidental que atingiram, particularmente, o Reino Unido de Portugal, Brasil e Algarves tem-se, em 1821, a abolição da censura, resultando no surgimento de vários jornais e panfletos em todas as províncias do Brasil, com destaque para o Rio de Janeiro, Bahia e Pernambuco.

O papel desempenhado pelos periódicos nas primeiras décadas do Oitocentos, a partir da difusão de uma nova cultura política tem sido tema de pesquisas nos últimos anos, sobretudo no campo da Históriaiv ${ }^{\mathrm{i}}$. Assim, os trabalhos elaborados até o momento têm procurado revelar as tramas e divergências políticas no processo de formação e consolidação do Estado imperial brasileiro, assim como analisar o surgimento de um novo vocabulário político coerente com as mudanças em curso. Nesse contexto, a imprensa periódica tem sido uma ferramenta fundamental, pelo que pode evidenciar, acerca de candentes problemáticas, tais como: Qual a importância desses jornais no impulsionamento do debate político à época? Que concepções expressavam sobre Nação, Pátria, Liberdade ou Constitucionalismo? Quem os elaboravam e quais seus vínculos políticos? Quem eram seus leitores? Como eram produzidos?

O historiador Marco Morel (2005), por exemplo, tem sido um dos grandes responsáveis pela análise crítica do periodismo no século XIX ao formular novas questões, mas também ao propor uma revisão historiográfica das produções que anteriormente se limitavam a fazer uma listagem dos periódicos sem a preocupação de vê-los como agentes históricos, mas sim como fonte fidedigna daquilo que retratavam. Traçando um quadro amplo sobre as pesquisas desenvolvidas nos séculos XIX e XX acerca da temática, o autor destaca trabalhos sobre a América hispânica e aponta as contribuições, limites e equívocos das abordagens, ${ }^{\mathrm{V}}$ advertindo que “Ainda hoje há quem confunda 'História da Imprensa' com um inventário de fontes" (MOREL, 2005, p. 1). Suas observações, criteriosas sobretudo no que se refere às questões teórico-metodológicas, são extremamente válidas para os pesquisadores da história da imprensa em qualquer temporalidade.

\section{O periodismo na Bahia: primórdios}

A Bahia ocupa um lugar de destaque no quadro das produções periodísticas e de panfletos desde as suas origens. Como dito anteriormente, em 1811 foi instalada a primeira tipografia na capitania, após a vinda da família real para a América portuguesa. Ao que tudo

\begin{tabular}{l|l} 
Revista RBBA & Revista Binacional Brasil Argentina
\end{tabular} 


\section{A IMPRENSA SERTANEJA COMO FONTE DE PESQUISA: APONTAMENTOS ACERCA DO JORNAL O COMBATE}

indica, a autorização para o seu funcionamento foi concedida pelo Príncipe Regente, no ano anterior, a Alexandre José Vieira de Lemos, mas foi com Manuel Antônio da Silva Serva, criador do periódico Idade d'Ouro do Brazil, que a Bahia teve o seu primeiro e único periódico por doze anos. ${ }^{\mathrm{vi}}$

O tortuoso processo de construção do Estado e da Nação brasileiros, no decorrer do século XIX, produziu uma diversidade de panfletos, periódicos e folhetos que buscavam dar conta das complexas questões políticas nas várias províncias do Brasil. Na Bahia, durante muito tempo os periódicos protagonizavam um intenso debate político sobre os novos rumos do Estado independente. A discussão sobre federalismo, centralização e republicanismo expressavam distintas posições, nas quais os jornais se mostravam instrumentos importantes como veículos de informação em um período de fortes tensões políticas.

Não se pode falar sobre o periodismo após o fim da censura no Brasil sem se referir a Cipriano Barata, dado a sua importância no debate político da época veiculado, principalmente, no periódico que produziu durante anos. Cipriano Barata, nascido na Bahia, teve sua vida agitada estreitamente ligada aos acontecimentos políticos ocorridos na província e mesmo fora dela desde, pelo menos, a Conjuração Baiana de 1798. Foi um ferrenho opositor de D. Pedro I e por meio das páginas do Jornal Sentinella da Liberdade criticou veementemente a falta de autonomia das províncias, o autoritarismo do Imperador e defendeu uma maior amplitude dos direitos dos povos no novo Estado independente.

Mesmo vivendo em condições adversas, Barata conseguiu manter o periódico por muitos anos, cuja produção fora interrompida algumas vezes durante as suas prisões. Além do jornal, deixou outros escritos, nos legando um material de grande valor para as pesquisas históricas. Graças ao trabalho de identificação, coleta e organização dos textos de Cipriano Barata feito por Marco Morel, é possível ter acesso à sua produção vigorosa, erudita e extremamente crítica nos primeiros anos de construção do Estado brasileiro (MOREL, 2008).

Ao que tudo indica, a circulação de diversos periódicos na Bahia foi permanente nos anos posteriores à Independência. Mesmo após o desaparecimento da gazeta Idade d'Ouro do Brazil, em 1823, vários panfletos e periódicos foram impressos na tipografia pertencente à família Serva após a morte de Manuel Serva. ${ }^{\text {vii }}$ Têm-se que no Recôncavo, em Cachoeira, o primeiro jornal aparece ainda em 1823 e muitos outros apareceriam nos anos seguintes com conteúdos políticos, literários, comerciais etc. 

ACERCA DO JORNAL O COMBATE

Dilton Oliveira de Araújo (2009), analisando o cenário político na Bahia após a ocorrência da Sabinada (1837-1838), evidenciou a importância dos periódicos para discutir questões relativas às variadas tensões em curso na província naqueles anos. Segundo o autor, existe um distanciamento entre a estabilidade política que teria se instalado na Bahia após a conturbada década de 1830, referida, inclusive por alguns estudiosos do período, e os receios manifestados pelas autoridades locais sobre a possibilidade de novos conflitos. A pacificação era algo desejado, mas não concretizada. A busca por esse objetivo animou grupos políticos e econômicos que adotaram caminhos variados para a sua efetivação, com destaque para o aumento da segurança local, sobretudo $O$ Guaycuru, no estímulo e participação no debate político no segundo reinado na província (ARAÚJO, 2009).

Araújo sustenta parte das suas argumentações por meio do uso das opiniões expressas nos principais periódicos conservadores da província. Para os redatores, era fundamental uma repressão exemplar aos rebeldes de modo a prevenir novos focos de contestação. Esta era a posição do Correio Mercantil ou do Lavrador do Recôncavo que defendiam ardorosamente o trono e a centralização do poder nas mãos do Imperador Pedro II. Na mesma direção, foram as providências para cercear a circulação do Jornal $O$ Guaycuru, de postura liberal e crítica, que teria levado seus editores a enfrentarem alguns processos judiciais (ARAÚJO, 2009). É de se supor que os habitantes do Recôncavo, assim como os das áreas interioranas, tiveram acesso a muitos desses periódicos, todavia, existem imensas lacunas para uma melhor compreensão do tema. ${ }^{\text {viii }}$

\section{Intelectuais e Imprensa nos Sertões baianos}

Quando se trata da presença da imprensa nos sertões da Bahia, uma das questões que chama a atenção é não somente a natureza dos conteúdos veiculados, mas também e não menos importante, a formação daqueles que produziam e, sobretudo, elaboravam o periódico: os editores e redatores. Não deixa de ser fascinante a qualidade do argumento, a racionalidade do pensamento político, em alguns casos a paixão pelo ato da escrita e a consciência de que, nas condições materiais de suas existências, poderiam interferir e contribuir para a alteração das experiências de vida da população ou, pelo menos, para iluminar os seus caminhos na busca daquilo que entendiam como uma nação menos excludente. 


\section{A IMPRENSA SERTANEJA COMO FONTE DE PESQUISA: APONTAMENTOS ACERCA DO JORNAL O COMBATE}

A atuação desses indivíduos se assemelha a tantos outros que exerceram, por meio dos seus escritos, uma importância fundamental na discussão sobre a formação da nação (SILVA, 2000; MICELI, 1984; SCHWARZ, 2009) cada um a seu modo, de forma que o panorama ideológico e cultural vivenciado por eles não pode ser bem compreendido sem uma análise mais detida dos diferentes aparelhos de produção e divulgação das concepções reproduzidos em seu tempo e lugar. Nesse sentido, o diálogo com Antonio Gramsci (1968; 2010) e JeanPaul Sartre (1994) é fundamental para o entendimento do papel dos intelectuais na sociedade moderna.

Para Gramsci, os intelectuais fazem parte de um todo organizado que legitima o domínio de certos grupos sociais, que, em determinados contextos, pode ser o fundamento de rupturas. Assim, o intelectual orgânico, como denomina, está sempre vinculado a uma determinada classe, ocupando um papel de grande importância na elaboração de sua posição hegemônica ou contra-hegemônica.

Sartre (1994), entretanto, considera que a figura do intelectual orgânico na classe proletária é inibida por sua própria condição social e econômica. Ele não o vê como um líder, mas como um interlocutor do povo no esclarecimento das suas mazelas, bem como das contradições econômicas e das possibilidades da sua superação. Concordando com Jacobelis (s.d.), o debate é importante e basilar e diz respeito à compreensão mais ampla do peso e da determinância que as ideias formuladas em um tempo podem ter nas relações humanas.

Nessa perspectiva, a trajetória de João Gumes chama a atenção. Nascido em Caetité, em pleno sertão da Bahia, em 1858, Gumes foi um autodidata e teve uma participação ativa na vida cultural da sua cidade. Foi escritor, advogado aprovisionado, secretário da Câmara Municipal, arquiteto, professor, músico, entre outras funções. Mas, sem dúvida, aquela que deixaria a sua marca nessas terras sertanejas foi como redator, editor e criador do Jornal $A$ Penna, além da publicação de alguns livros, como O Sampauleiro (1929), Os Analphabetos (1928). O jornal foi criado em 1897 e, mesmo após a sua morte, em 1930, circulou por mais de uma década sob o comando de seus filhos. Nas suas páginas, Gumes expressava seu pensamento modernista no qual o Brasil florescia deixando para traz seu passado escravista e atrasado. ${ }^{\text {ix }}$

Dado a diversidade e riqueza dos temas tratados em suas páginas, bem como a importância das suas obras, nos últimos anos pesquisadores têm se debruçado sobre os seus

\begin{tabular}{l|l} 
Revista RBBA & Revista Binacional Brasil Argentina
\end{tabular} 

ACERCA DO JORNAL O COMBATE

escritos, na tentativa de compreender sua percepção e ideário. De fato, muitas das suas preocupações no limiar da República remetem ao abandono dos habitantes do sertão pelas autoridades políticas, destacando-se suas denúncias a respeito de uma nação que via como incompleta justamente por constatar que muitos dos problemas sociais, como o analfabetismo, por exemplo, se perpetuavam, mesmo depois da implementação do novo regime republicano e das promessas feitas por aqueles que lideraram o processo. Assim, grande parte dos escritos de Gumes questionavam o lugar ocupado pelos sertões no projeto de nação na nascente República brasileira. (REIS, 2010; PIRES, 2011).

Esse é o caso também de outros indivíduos que, nas primeiras décadas do século XX, se destacaram como editores, redatores e escritores em Vitória da Conquista, como Laudionor Brasil, Erathosthenes Menezes, Camillo de Jesus Lima, entre outros, constituindo um seleto grupo que dominava os instrumentos da escrita em um momento que a circulação do saber e do conhecimento era bastante limitada (MEIRA, 2017; SOUZA; MAGALHÃES, s/d). Os seus escritos buscavam, em linhas gerais, chamar a atenção para as precárias condições de vida da população sertaneja, ao mesmo tempo em que se viam como portadores de alternativas para as mudanças julgadas necessárias. De modo semelhante a João Gumes e a despeito de diferenças de concepções, esses intelectuais denunciavam a incompletude da Nação brasileira, haja vista que, para eles, o sertão ainda precisava ser incorporado ao projeto civilizacional. Desse modo, tiveram um papel relevante na criação de uma narrativa que conferisse identidade às áreas sertanejas, enfatizando as suas singularidades sem perder de vista a sua inserção em uma concepção mais ampla de nação.

Neste cenário e, como dito anteriormente, o jornal $O$ Combate ocupa um lugar importante não somente pela diversidade do seu conteúdo, como também pelos posicionamentos assumidos por seus redatores nas primeiras décadas do Brasil Republicano.

\section{O Jornal $O$ Combate e suas possibilidades de pesquisa}

Vitória da Conquista surge como vila no ano de 1840, quando foi desmembrada da Vila de Santana do Príncipe de Caetité. O povoamento e a ocupação da região, outrora conhecida como Sertão da Ressaca, decorreu do projeto colonizador incentivado pelo Estado português em meados do século XVIII, marcando as origens da urbe pela violência contra a 
A IMPRENSA SERTANEJA COMO FONTE DE PESQUISA: APONTAMENTOS

\section{ACERCA DO JORNAL O COMBATE}

população nativa e africana, tornadas escravas (SOUSA, 2001).

$\mathrm{O}$ arraial, e posteriormente vila, se estabeleceu como ponto de passagem de homens, animais e mercadorias que vinham do sertão para o litoral ou o norte de Minas, ou faziam o percurso inverso. Ainda que não tivesse a expressão econômica de outras localidades, aos poucos o local vai adquirindo maior movimentação e densidade populacional, sobretudo nos anos 1940, cem anos após a instalação da vila, com a abertura de estradas que facilitavam ainda mais o transporte regional. As pesquisas desenvolvidas nos últimos anos sobre a localidade têm evidenciado questões importantes acerca do cotidiano, economia e conflitos numa vila do interior do sertão (SOUSA, 2001; SANTOS, 2014; MIGUEL, 2000; NOVAIS, 2008).

Responsável pelas principais ações de ocupação do território, a família Gonçalves da Costa, entrelaçada com outras famílias proprietárias na região, conduziria e controlaria o poder político local por muitos anos. As divergências políticas entre grupos rivais pelo controle do poder municipal, a exemplo do que ocorria em outros lugares do Brasil, foram responsáveis por conflitos violentos que marcaram a história e a memória da cidade (MEDEIROS, 2009; SOUZA, 2010; IVO, 2017). Assim, as primeiras décadas republicanas apresentavam, por um lado, os desafios para a inserção do Brasil em um novo quadro político e econômico decorrente da abolição da escravatura (1888) e da Proclamação da República (1889) e, por outro, os problemas da crescente desigualdade social e aumento da pobreza.

É neste contexto de efervescência que surge, em 11 de agosto de 1929, o Jornal $O$ Combate, criado por Laudionor de Andrade Brasil. Como alguns intelectuais do seu tempo, Laudionor Brasil, desde cedo, mostrou grande inquietude com os problemas políticos, culturais e sociais do país e, em particular, da cidade. Diretor de escola, professor, poeta, as poucas referências a ele destacam sua habilidade para, inclusive, reunir um grupo de indivíduos que, mesmo com opiniões divergentes, decidiu assumir a condução do jornal. Este é o caso, por exemplo, de Camillo de Jesus Lima, responsável por muitas das matérias veiculadas no periódico. Dono de um pensamento crítico em virtude da sua aproximação com a teoria marxista e cioso das questões não apenas nacionais, mas também internacionais, leitor e escritor refinado, os escritos de Lima surpreendem em se tratando das condições adversas para o exercício da função naquela época (MEIRA, 2017).

Outros jornais existiram antes de $O$ Combate, como, por exemplo, o A Conquista, 

ACERCA DO JORNAL O COMBATE

criado em 1911, e que teria sido o primeiro a ser produzido na cidade. Todavia, a descontinuidade em sua produção, assim como a perda de muitos de seus exemplares, infelizmente impedem uma análise mais apurada e ampliada sobre a presença dessa imprensa em áreas sertanejas. ${ }^{\mathrm{x}}$

Circulando por mais de trinta anos até a década de 1960, O Combate revela-se um instrumento importante para o pesquisador compreender a dinâmica de uma cidade sertaneja no século XX, mas não apenas isso. Das suas páginas ressoam questões importantes que transfiguram as preocupações candentes daqueles que estavam em sua direção. São temas relacionados aos acontecimentos e problemas políticos e econômicos mundiais e, notadamente, os desdobramentos da Revolução Russa de 1917, as grandes guerras mundiais, a crise de 1929, mas também questões que diziam respeito diretamente aos anseios e demandas das populações sertanejas, como o analfabetismo ou as dificuldades para frequentar uma escola, bem como a falta de atenção dos poderes públicos com as regiões mais afastadas dos centros decisórios do poder.

Em sentido mais amplo, as preocupações que certamente envolviam os principais responsáveis pela elaboração do jornal se assemelhavam àquelas já expressas por João Gumes no A Penna, qual seja, a de fazer uso da palavra escrita para escancarar as mazelas de uma população desfavorecida que, a despeito da mudança do regime político, permanecia à mercê dos interesses escusos de certos políticos. Com tiragem semanal, produzido de maneira rudimentar e artesanal, esses periódicos foram fundamentais no processo de formação de uma cultura política local.

Alguns trabalhos iniciais têm evidenciado a importância da imprensa em Vitória da Conquista como fonte documental, notadamente no que se refere às questões relativas à educação e à política local. Isso pode ser percebido, principalmente, em estudos desenvolvidos por Daniella Moura Rocha, Lívia Diana Rocha Magalhães, Maria Cristina Nunes Cabral, que discutem o papel desempenhado por alguns intelectuais na cidade, professores, nas primeiras décadas do republicanismo, e sua importância para o entendimento de um projeto político modernizante expresso em suas práticas cotidianas e, sobretudo, em escritos jornalísticos (SOUZA, 2009, MAGALHÃES, 2009; CABRAL, 2009). Existem também estudos acerca das relações políticas e conflitos locais desencadeados por grupos familiares interessados na manutenção ou ocupação do poder. O estudo de Belarmino de 


\section{A IMPRENSA SERTANEJA COMO FONTE DE PESQUISA: APONTAMENTOS ACERCA DO JORNAL O COMBATE}

Jesus Souza (2010) analisou a efervescência política na cidade, que inter-relacionava partidos, grupos políticos e os diversos interesses envolvidos na disputa pelo controle da municipalidade entre os anos 1962 e 1992. A pesquisa desenvolvida por Esmeralda Guimarães Meira (2017), por meio de uma análise ampla e aprofundada sobre a trajetória de Camillo de Jesus Lima, permite compreender o processo de construção do pensamento político e social daquele que, possivelmente, fora o mais destacado intelectual atuante na cidade.

De maneira mais ampla, os estudos permitem concluir que os debates que permeavam as páginas da imprensa local, principalmente aquelas difundidas pelo jornal $O$ Combate, dado a formação intelectual dos seus redatores, como já mencionado, evidenciam que não estavam dissociados das discussões ocorridas no âmbito nacional ou mesmo internacional. Em outras palavras, existia uma dinâmica de produção e elaboração local com suas particularidades que, todavia, dialogavam estreitamente com o que ocorria em outros lugares. Esta é uma questão importante que precisa ser levada em consideração para permitir uma compreensão mais totalizante das formulações e contradições postas pelos homens das letras. A análise da imprensa local possibilita revelar não somente a dinâmica política e cultural dos sertões, como também desconstruir certa visão tradicional de isolamento, atraso e paralisia dessas áreas, ainda tão vigente nos dias atuais.

Acreditamos que, apesar das valiosas contribuições já postas sobre o papel da Imprensa em Vitória da Conquista, ainda há muito o que explorar. A discussão sobre a concepção de nação e de identidade nacional, questões relativas à expansão urbana, as contradições e tensões daí decorrentes, uma análise sobre as imagens retratadas em suas páginas. assim como fotografias, desenhos, etc., as manifestações culturais, o pensamento político dos redatores e as relações entre a Imprensa e o poder são, certamente, algumas das temáticas importantes a serem exploradas pelos pesquisadores na imprensa periódica (LUCA, 2012).

\section{Considerações Finais}

Os estudos históricos sobre a imprensa periódica nos sertões da Bahia têm apresentado resultados significativos, todavia, ainda há muito a ser explorado pela dimensão que adquiriu no período aqui analisado. Tentou-se mostrar nesses apontamentos que o periódico, como 

ACERCA DO JORNAL O COMBATE

fonte documental, possui uma complexidade que necessita ser apreendida antes de trata-la meramente como registro de fatos e acontecimentos do cotidiano local. No caso específico do Jornal $O$ Combate, produzido e elaborado por um grupo de intelectuais sertanejos ao longo do século XX, é perceptível a força das palavras impressas. São textos que chamam a atenção, em sua grande maioria, pela capacidade de formulação dos seus redatores e pelo que podem revelar acerca das concepções que possuíam.

Desse modo, sobressai nos textos o posicionamento político, ora de maneira mais explícita e virulenta, ora de modo mais velado e contido. É preciso, assim, estar atento às contradições que possivelmente apresentam, como também perceber que a expressão das ideias de seus autores não é um mero reflexo de concepções já definidas ou, intencionalmente como já se afirmou, uma "falsificadora da realidade" (MOREL, s/d). Os periódicos aparecem como um espaço de reflexão, de proposição, mas também de recriação, como um instrumento ativo e fundamental para ampliar os nossos conhecimentos acerca das dinâmicas regionais distanciadas dos poderes centrais da nação republicana.

\section{REFERÊNCIAS}

ARAÚJO, Dilton O. O tutu da Bahia: transição conservadora e formação da nação, 18381850. 1. ed. Salvador: EDUFBA, 2009.

CABRAL, M. C. N. ; MAGALHAES, L. D. R. . O ideal Modernizador da Educação em Vitória da Conquista - BA entre as décadas de 1930 a 1950. In: VIII Seminário Nacional de Estudos e pesquisas "História, Sociedade e Educação no Brasil", Campinas/SP, HISTEDBR, 2009.

DINIZ, J. Péricles. Uma breve trajetória da Imprensa no Recôncavo da Bahia durante o século XIX. Disponível em: http://www.ufrgs.br/alcar/encontros-nacionais-1/encontros-nacionais/7oencontro-2009-1/Uma\%20breve\%20trajetoria\%20da\%20imprensa.pdf. Acesso 02.03.2020)

GRAMSCI, Antonio. Cadernos do Cárcere. 5 ed., Rio de Janeiro: Civilização Brasileira, 2010. 1968.

Os intelectuais e a organização da cultura. Rio de Janeiro, Civilização Brasileira,

FERNANDES, Luís. Revista Histórica. Cem anos de jornalismo em Vitória da Conquista. Vitória da Conquista: Brasil Artes Gráficas, 2011.

FERREIRA, Luan Vinicius et al. A origem do jornal impresso em Vitória da Conquista (Disponível em: https://focanativa.wordpress.com/2016/03/14/a-origem-do-jornal-impresso-emvitoria-da-conquista/ Acesso em 01.03.2020. 


\section{A IMPRENSA SERTANEJA COMO FONTE DE PESQUISA: APONTAMENTOS ACERCA DO JORNAL O COMBATE}

IVO, Isnara Pereira. O Anjo da morte contra o santo lenho: poder, vingança e cotidiano no sertão da Bahia. 2. ed. Vitória da Conquista: Edições Uesb, 2017.

JACOBELIS, Paola Gentile. O problema dos intelectuais no mundo contemporâneo sob duas perspectivas: organizadores da cultura ou expressão das contradições sociais. Disponível em file:///C:/Users/caiod/Downloads/8095-Texto\%20do\%20artigo-19621-1-10-20140814.pdf. Acesso em 27.04.2019.

LUCA, Tania Regina de. Imprensa periódica e escrita da História: algumas observações. In: REIS, Júlia Bianchi (Org.). Anais do I seminário de Pós-Graduandos em História da UFF. Estudos de Imprensa no Brasil. Niterói: UFF, 2012, p. 12-15.

MEDEIROS, Ruy Hermann Araújo. Política, família e educação em Vitória da Conquista na primeira metade do século XX. Revista HISTEDBR On-line, Campinas, n.36, p. 1115-123, dez.2009 - I.

MEIRA, Esmeralda Guimarães. O arquivista de si - História e Memória do escritor Camillo de Jesus Lima. Vitória da Conquista: UESB, 2017 (Tese de Doutorado).

MICELI, Sérgio (Org.). Estado e cultura no Brasil. São Paulo: IDESP, 1984.

MIGUEL, Antonieta. Vida material e cotidiano na Imperial Vila da Vitória na segunda metade do século XIX. Salvador: UFBa, 2000 (Dissertação de Mestrado)

MOREL, Marco. O surgimento da imprensa no Brasil: questões atuais. Rio de Janeiro, Maracanan, n. 3, p. 17-30, 2005.

(Org.). Cipriano Barata. Sentinella da Liberdade e outros escritos (1821-1835). São Paulo: EDUSP, 2008.

Imprensa periódica no século XIX. Rede Memória. Rede Memória Virtual Brasileira. Disponível em https://bndigital.bn.gov.br/dossies/rede-da-memoria-virtualbrasileira/imprensa/imprensa-periodica-no-seculo-xix/. Acesso em 03.03.2020

NOVAIS, Idelma Aparecida F. Produção e Comércio na Imperial Vila da Vitória - 18401888. Salvador: UFba, 2008 (Dissertação de Mestrado).

OLIVEIRA, Jeremias Macário de. A Imprensa e o Coronelismo no Sertão do Sudoeste. Vitória da Conquista: edições UESB, 2005

PIRES, Maria de Fátima Novais. Hommes de Letrres na "Corte do Sertão": João Gumes e a escrita social. Revista Veredas da História, Ano IV - Ed. 2 - 2011, p. 151-166.

REIS, Joseni Pereira Meira. Instâncias formativas, modos e condições de participação nas culturas do escrito: o caso de João Gumes (Caetité, Bahia, 1897 a 1928). Belo Horizonte: UFMH, 2010. 

ACERCA DO JORNAL O COMBATE

SANTOS, Paulo Henrique Duque. Légua tirana: sociedade e economia no alto sertão da Bahia. Caetité, 1890-1930. São Paulo: USP, 2014 (Tese de Doutorado).

SARTRE, Jean-Paul. Em defesa dos intelectuais. São Paulo: Ed Ática, 1994.

SCHWARZ, Roberto. Cultura e política. 3 ed. São Paulo: Paz e Terra. 2009.

SILVA, Paulo Santos. Âncoras de tradição. Luta política, intelectuais e construção do discurso histórico na Bahia (1930-1949). Salvador: EDUFBA, 2000.

SODRÉ, Nelson Werneck. História da Imprensa no Brasil. Rio de Janeiro: Mauad, 1999.

SOUZA, Belarmino de Jesus. Uma polis sertaneja, fora do eixo e fora do centro: imprensa e memória nas disputas políticas em Vitória da Conquista (1962-1992). Salvador: UFBA, 2010 (Tese de Doutorado).

SOUZA, Daniela Moura R. de. Memória de Professores Intelectuais como Interlocutores do Republicanismo em Vitória da Conquista entre os anos de 1910 até 1945. Vitória da Conquista: UESB, 2009 (Dissertação de Mestrado).

SOUZA, Daniela Moura R. de; MAGALHÃES, Lívia Diana Rocha. Não fazem mal as musas aos... alfaiates: Um professor intellectual em Vitória da Conquista - Bahia - O caso de Laudionor de Andrade Brasil. Revista HISTEDBR on-line. Disponível em: https://periodicos.sbu.unicamp.br/ojs/index.php/histedbr/article/view/8640265/7824.

Acessado em 25.02.2020.

SOUSA, Maria Aparecida Silva de. Bahia: de capitania a província. São Paulo, Universidade de São Paulo, 2008 (Tese de Doutorado).

Conjuntura política nas páginas da Gazeta Idade d’Ouro do Brazil (Bahia, 18111820). In: BERTONI, Luci; MORORÓ, Leila Pio; CAMARGO, Caudinei (Orgs). Desafios epistemológicos das Ciências na atualidade. São Paulo: Canal 6, 2013, p. 151-163.

TEIXEIRA, Byron de Castro Muniz. Memória, República e Sertão em um Periódico Sertanejo (A PENNA, 1897-1930). UESB, 2012 (Dissertação de Mestrado).

\section{Notas}

\footnotetext{
i Professores Sérgio Lessa (UFAL), Esmeralda Guimarães Meira (UNEB/Campus VI), Joseni Pereira Meira Reis (UNEB/Campus XI) e Ruy Hermann Araújo Medeiros (UESB).

ii Agradecemos a colaboração de Jailton Ribeiro, responsável pelo acervo do Arquivo Municipal de Vitória da Conquista, assim como os discentes do Curso de História da UESB que atuaram como bolsistas de extensão no projeto, Cleiton Dias e Luiz Alexandre Brandão Freire, e a monitora voluntária Larissa Bispo dos Santos.

iii Apesar de 1808 ser uma data inaugural da instalação de tipografias no Brasil, circulavam na América portuguesa periódicos de língua inglesa, francesa, espanhola e portuguesa. Segundo Marco Morel (2005, p. 24), entre os anos de "1749 e 1807 foram contabilizados trinta periódicos de caráter literário, musical, científico, histórico, comercial e de agricultura". Como observa o autor, as condições de circulação e de sua recepção ainda estão para ser estudadas.
} 


\footnotetext{
iv Acerca, acessar a Revista do Programa de Estudos Pós-Graduandos em História e do Departamento de História da PUC-SP, num. 35, de julho-dezembro de 2007. Disponível em: http://www4.pucsp.br/projetohistoria/downloads/volume35/ATT06511.pdf Acessado em 01.03.2020.

" Sobre o periodismo nas primeiras décadas do século XIX, ver: OLIVEIRA, Cecília Helena de S. O disfarce do anonimato: O debate político através dos folhetos (1820-1822). São Paulo: USP, 1979; LUSTOSA, Isabel. Insultos impressos. A guerra entre os jornalistas na Independência (1821-1823). São Paulo: Cia. das Letras, 2000; NEVES, Lúcia Maria B. P. Corcundas e constitucionais. A cultura política da Independência (1820-1822). Rio de Janeiro: Revan/Faperj, 2003.

vi Durante muito tempo acreditou-se que o primeiro a receber uma autorização para a instalação de uma tipografia teria sido Manuel Antônio da Silva Serva. Não se sabe ao certo as razões para que Alexandre José Vieira de Lemos não tenha levado adiante a sua tipografia (IPANEMA; IPANEMA, 2010). O Idade d'Ouro do Brazil começou a circular no dia 14 de maio de 1811 e, com poucas interrupções, circulou até o ano de 1823, nas vésperas da consolidação da Independência do Brasil na Bahia (SOUSA, 2013).

vii Foram diversas folhas impressas na Tipografia Viúva Serva e Carvalho. A maioria de curta duração. (Cf. DINIZ, 2009).

viii As informações sobre a presença de periódicos nos sertões da Bahia são ainda mais raras. As péssimas condições da maioria dos arquivos públicos e a ausência de cuidados para com a conservação de fontes documentais dificultam, sobremaneira, o acesso àqueles que, possivelmente, existiram em algumas cidades. $\mathrm{Na}$ contramão desse processo, temos, até o momento, alguns estudos sobre o jornal A Penna, criado em Caetité no final de século XIX por João Gumes. Este jornal teve uma vida relativamente longa, destoando da maioria dos seus similares da época, que existiam por um curto período, e que, graças ao trabalho da equipe do Arquivo Municipal de Caetité, boa parte da coleção do jornal pôde ser recuperada e colocada à disposição do público.

ix Segundo Oliveira (2005), antes do Jornal A Penna João Gumes publicou uma única edição do periódico $O$ Caetiteense, em 1896.

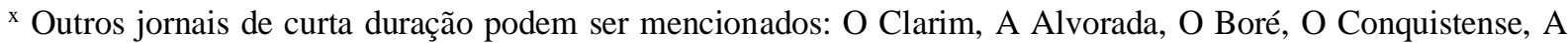
notícia, alguns de caráter literário (OLIVEIRA, 2005; CABRAL \& MAGALHÃES, 2009; FERNANDES, 2011; FERREIRA et al, 2016).
}

\section{Sobre os autores}

Maria Aparecida Silva de Sousa possui graduação em Licenciatura Plena em História pela Universidade Estadual do Sudoeste da Bahia, Especialização em História do Brasil pela Pontifícia Universidade Católica de Minas Gerais, Mestrado em História pela Universidade Federal de Minas Gerais e Doutorado em História Social pela Universidade de São Paulo (2009). Publicou, pela Edições UESB, A Conquista do Sertão da Ressaca: povoamento $e$ posse da terra no interior da Bahia. É professora titular do Departamento de História da Universidade Estadual do Sudoeste da Bahia desde 1999, membro do Centro de Documentação Albertina Vasconcelos/Museu Pedagógico da UESB. Desenvolve pesquisas nas áreas de História do Brasil/História da Bahia, com foco no processo de formação do Estado e da Nação brasileiros, conflitos políticos e dinâmicas dos sertões da Bahia.

Lattes: http://lattes.cnpq.br/1717712438822665

Endereço eletrônico: mariacida3@yahoo.com.br

José Rubens Mascarenhas de Almeida é Doutor em Ciências Sociais pela Pontifícia Universidade Católica de 
São Paulo; Pós-doutor pela Universidad Nacional Autónoma de México; docente do Departamento de História da Universidade Estadual do Sudoeste da Bahia, campus de Vitória da Conquista -BA/Brasil. Pesquisador do Museu Pedagógico/UESB e do Núcleo de Estudos de Ideologia e Lutas Sociais - PUCSP. Coordena o Grupo de Estudos de Ideologia e Lutas de Classes (GEILC/MP/UESB).

Lattes: http://lattes.cnpq.br/3920900756591288

ORCID: https://orcid.org/0000-0002-0232-5461

Endereço Eletrônico: rubens.mascarenhas@uesb.edu.br 